\title{
Sampled grating DBR laser as a spectroscopic source in multigas detection at $1.52-1.57 \mu \mathrm{m}$
}

\author{
K.Boylan, V.Weldon, D.McDonald, J.O'Gorman and J.Hegarty
}

\begin{abstract}
The first application is reported of multigas sensing using a widely tuneable sampled grating DBR laser with a tuning range $1520 \leq \lambda \leq 1570 \mathrm{~nm}$. The laser diode consists of four independently biased sections, two sampled gratings, a phase section and a gain section. Setting the laser emission wavelength within its broad tuning range is achieved by tuning the front and back grating mirrors. Three gases $\mathrm{H}_{2} \mathrm{~S}, \mathrm{C}_{2} \mathrm{H}_{2}$ and $\mathrm{CO}_{2}$ with absorption features within the $30 \mathrm{~nm}$ tuning range of the device were targeted and successfully detected. In addition, minimum detection limits were estimated using wavelength modulation spectroscopy. Initial results demonstrate the value of this device as a light source in absorption spectroscopy based multigas detection systems.
\end{abstract}

\section{Introduction}

The development of widely tuneable lasers has been driven by the growth of wavelength division multiplexing (WDM), due to the greater capacity requirements of optical networks in the telecommunications arena. The most promising widely tuneable laser structures reported in recent years include multisection DBR lasers [1] with tuning ranges $\leq 10 \mathrm{~nm}$ and SG-DBR lasers [2] with discontinuous tuning capability of $\leq 57 \mathrm{~nm}$. Other widely tuneable structures such as the SSG-DBR [3] and the GCSR [4] lasers have achieved tuning ranges of $\cong 100 \mathrm{~nm}$ while retaining operating characteristics similar to those of distributed feedback (DFB) lasers.

Significant research has been carried out in the application of high quality single-mode laser diodes developed for the telecommunications industry as light sources in tuneable laser diode absorption spectroscopy (TDLAS) gas detection systems. These have now become products and technologies. Application areas of TDLAS include the monitoring of industrially and environmentally important gases for health and safety purposes. There is a growing need to monitor a wider variety of atmospheric pollutants such $\mathrm{HCN}, \mathrm{HI}$ and $\mathrm{NH}_{3}$ with systems that are capable of selective multispecies detection in real time. The use of widely tuneable lasers, such as the SG-DBR device as a light source in TDLAS, has the potential to eliminate the need for multiple laser sources to monitor more than one gas $[5,6]$. This results in significant advantages in the application of these laser technologies to environmental and process monitoring industries.

(C) IEE, 2001

IEE Proceedings online no. 20010191

DOI: $10.1049 /$ ip-opt:20010191

Paper first received 26th June and in revised form 7th December 2000

The authors are with the Optronics Ireland, Physics Department, Trinity College, Dublin 2, Ireland

\section{Background}

The SG-DBR laser has four independently biased sections as illustrated in Fig. 1: two sampled gratings $\left(I_{f}, I_{b}\right)$, a passive phase control $\left(I_{p}\right)$ and an active section $\left(I_{g}\right), I_{f}, I_{b}$, $I_{p}$ and $I_{g}$ refer to the drive currents for the respective sections. A sampled grating consists of a conventional grating which has elements periodically removed along its length. This sampling of the grating results in it having a comb-like reflection spectrum with periodic maxima. The two grating sections have slightly different Bragg periods which results in the peaks of the reflection spectrum of both mirrors being slightly mismatched. When biased above threshold, lasing occurs at the wavelength where the reflection maxima for the front and back sampledgrating sections are coincident in wavelength. Independent tuning of each sampled-grating section's peak reflection wavelength is performed via independently controlled current injection into each passive section, where plasma and band-filling effects [3] mediate the tuning behaviour. Details of the SG-DBR widely tuning mechanism are reported elsewhere [3].

To tune between two reflection maxima or supermodes, the front and back grating sections must be tuned simultaneously. Tuning between supermodes is limited by free carrier absorption in the Bragg mirror sections, which effects both the achievable output power and side-mode suppression ratio (SMSR). In addition, the cavity mode can be tuned continuously between two longitudinal modes using the phase control section. A combination of these

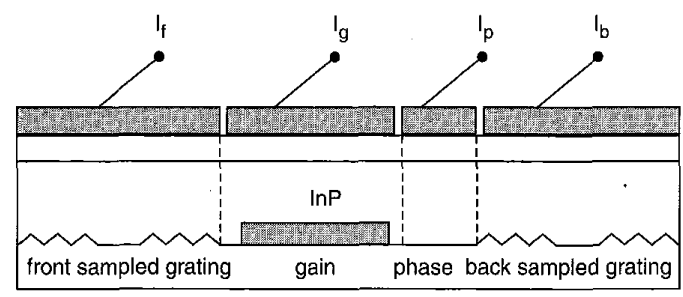

Fig. 1 Schematic of four-section sampled grating DBR laser diode consisting of two sampled grating sections, phase section and gain section 
tuning approaches leads to quasicontinuous access to all wavelengths within the wider laser tuning range. Indeed, the maximum tuning range of the laser is limited by the repeat mode spacing, which is a function of the Bragg period difference between the mirror grating sections [2].

We report the use of a SG-DBR laser in multigas detection and analysis using wavelength modulation spectroscopy [7]. The exemplar gases chosen for investigation are $\mathrm{C}_{2} \mathrm{H}_{2}, \mathrm{H}_{2} \mathrm{~S}$ and $\mathrm{CO}_{2}$. Specifically, the absorption lines in the P-branch of the relatively strong $\left(v_{1}+v_{3}\right)$ combination band of $\mathrm{C}_{2} \mathrm{H}_{2}$ at $1.530 \mu \mathrm{m}$ [8], the $\left(v_{1}+v_{2}+v_{3}\right)$ combination band of $\mathrm{H}_{2} \mathrm{~S}$ at $1.570 \mu \mathrm{m}$ [9] and the $\left(2 v_{1}+2 v_{2}+v_{3}\right)$ overtone/combination band of $\mathrm{CO}_{2}$ at $1.575 \mu \mathrm{m}$ [10] were targeted.

\section{SG-DBR static characterisation}

A SG-DBR laser diode (mounted as chip-on-carrier) was placed on a temperature-controlled copper block and electrical connections made to each section via needle probes. The phase section was left open-circuited while the front and back grating sections and the gain section were driven from GPIB-controlled constant-current sources. The controlling PC collected all data from the diagnostic equipment using a GPIB interface. For spectral characterisation the light emitted by the laser was collected with a single-mode fibre and measured with an optical spectrum analyser. Fig. 2 shows the measured emission spectrum of the laser. The device lases in a single mode, with a SMSR of $40 \mathrm{~dB}$. The other clearly visible modes, with a mode spacing of $6 \mathrm{~nm}$, are supermodes resulting from the sampling of the DBR mirror elements. The gain section tuning rates, as a function of temperature $T$ and gain section current $I_{g}$, were measured while the passive sampled-grating sections were unbiased and the phase section remained open-circuit. These measured wavelength tuning rates are $\Delta \lambda / \Delta T=1.76 \times 10^{-1} \mathrm{~nm} /{ }^{\circ} \mathrm{C}$ and $\Delta \lambda / \Delta I_{g}=$ $3.96 \times 10^{-3} \mathrm{~nm} / \mathrm{mA}$, as a function of temperature and current, respectively.

The light $(L)$-current $(I)$ characteristic of the SG-DBR was measured at $25^{\circ} \mathrm{C}$ where the light collected by the fibre is measured as a function of gain-section current. The

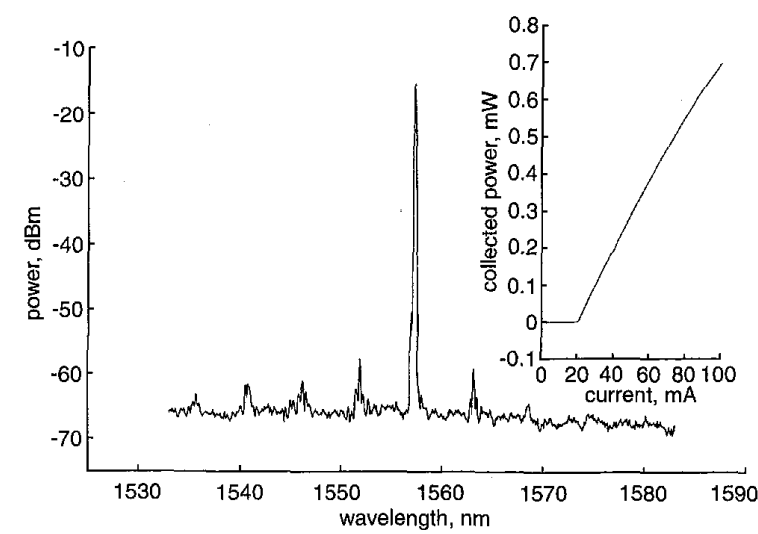

Fig. 2 Single-mode operation of $S G-D B R$ laser above threshold at $25^{\circ} \mathrm{C}$. Other possible cavity modes are also visible. Measured light-current (L-I) curve at a temperature of $25^{\circ} \mathrm{C}$ in shown inset

lasing threshold of the SG-DBR laser diode is $20 \mathrm{~mA}$, with the measured $L-I$ curve displaying good linearity [see inset in Fig. 2], a characteristic that is required for high-sensitivity harmonic spectroscopy gas detection [11].

Moving to more advanced characterisation of the diode, the device grating sections were current tuned over the range $0 \leq I \leq 20 \mathrm{~mA}$ at $T=25^{\circ} \mathrm{C}$. Fig. 3 shows a contour graph of the lasing emission wavelength as a function of front and back grating-section currents. The discontinuous tuning range of the laser was found to be $50 \mathrm{~nm}$, as illustrated in Fig. $4 a$. The contours illustrated in Fig. 3 clearly identify the boundaries at which a discontinuity, a supermode hop, occurs. The observed overlap (the repeat mode wavelength spacing [2]) indicated in Fig. $4 b$ in this contour graph occurs when the overlap of the reflection spectra of both sampled-grating reflections repeat. This repeat mode spacing is approximately $50 \mathrm{~nm}$ for the current laser. Access to all wavelengths between two supermodes is clearly demonstrated in Fig. $4 b$, whereby simultaneously tuning both sampled-grating sections enabled continuous tuning up to $6 \mathrm{~nm}$. This tuning behaviour is achieved by simultaneously driving $I_{f}$ and $I_{b}$ to a stable point between two supermode hops, as shown in

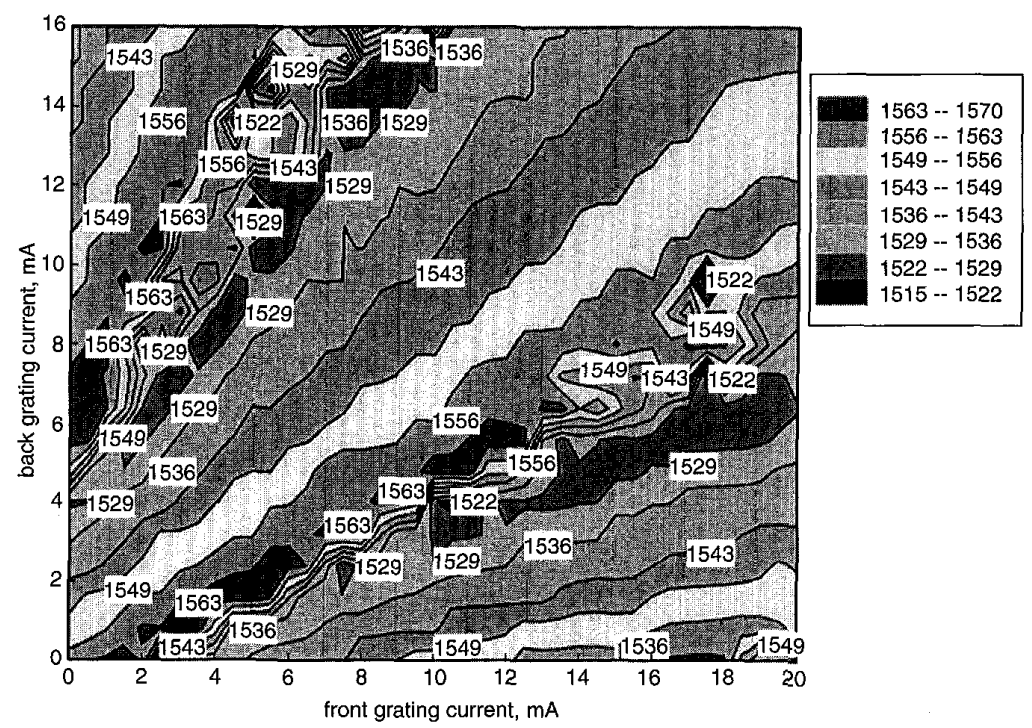

Fig. 3 Emission wavelength of $S G-D B R$ as function of current injected into front and back gratings over range $0 \leq 1 \leq 20 \mathrm{~mA}$ and $0 \leq 1 \leq 16 \mathrm{~mA}$, respectively $I_{\mathrm{g}}=80 \mathrm{~mA}$, at $25^{\circ} \mathrm{C}$ 

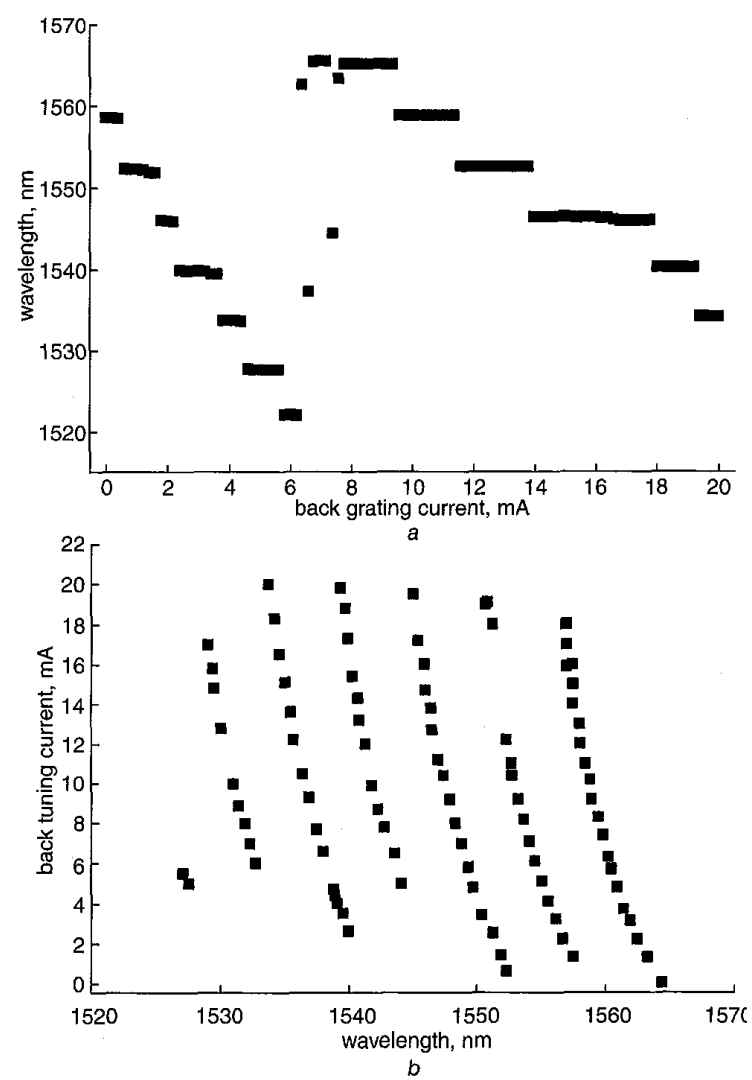

Fig. 4 Two tuning regimes employed

$a$ Discontinuous tuning of back section over current ranges $0 \leq \mathrm{I} \leq 20 \mathrm{~mA}$ at $25^{\circ} \mathrm{C}$ while front section is unbiased

$b$ Simultaneous tuning of both sections (only back sampled grating section current shown) to tune between two supermodes.

Fig. 3. A best-fit line to achieve optimum laser performance is chosen on the basis that the distance to both supermode jumps is maximised so that mode stability is optimised. The grating-section currents are then incremented in equal steps along this line. By repeating this tuning we were able to quasicontinuously access $\geq 30 \mathrm{~nm}$.

The output power from the laser was measured using an integrating sphere. A $\times 20$ objective lens was required to collect the emitted power (approximately $80 \%$ ) due to mechanical difficulties in using the integrating sphere on its own. The maximum integrated power was $500 \mu \mathrm{W}$ when both gratings were unbiased at $25^{\circ} \mathrm{C}$. This power dropped by greater than an order of magnitude at the extremes of the current tuning range used.

\section{Application to gas sensing}

In this work the SG-DBR widely tuneable laser diode performance as a light source for TDLAS-based gas detection is assessed. In the near-infrared region of the spectrum the absorption linestrength of gases is weak. Hence, to improve the absorption SNR it is conventional to employ a WMS $[12,13]$ based TDLAS technique. In WMS the emission wavelength of the laser diode is modulated usually with a sinusoid at some frequency $(\simeq \mathrm{kHz} / \mathrm{MHz})$ while the laser emission line is slowly ramped across the gas absorption line of interest. Simultaneously the transmitted light attenuation in the absorption gas is measured as a function of laser wavelength. In this technique the modulation frequency is low compared with the targeted absorption linewidth, which is usually a few $\mathrm{GHz}$ at atmospheric pressure, and the modulation amplitude is comparable with the absorption linewidth. Wavelength-dependent absorption by the gas transforms the wavelength modulation to an amplitude modulation of the transmitted beam that varies as the emission wavelength is scanned across the absorption feature.

Weak absorption signals may by detected in this manner since the method strongly discriminates against wavelength independent signals. The WMS technique when optimised, is capable of measuring very weak absorbance signals $\left(10^{-7}\right)$ [13]. Typically the experimental procedure requires that the laser emission wavelength be set to a value close to the absorption line of interest by adjusting the current to the front and back grating sections of the laser diode. The injection current to the gain section of the device is then slowly increased to provide fine wavelength tuning across the absorption line, while simultaneously a sinewave modulation of frequency $f$ is superimposed on the DC ramp. As the laser emission wavelength scans the absorption feature the change in optical transmission leads to a distortion in the transmitted waveform that alters its harmonic content. Consequently, a weak absorption signal may be synchronously detected at the second harmonic of the modulation frequency $2 f$.

The SG-DBR laser was used in a WMS experimental setup shown in Fig. 5 to perform measurements on individual absorption lines of three gases. To determine the low detection limit for a particular gas an absorption feature within the wavelength tuning range of the device was first established by obtaining a broad absorption spectrum. This was achieved by amplitude modulation of the laser intensity with a light chopper at $3 \mathrm{kHz}$ and synchronous lock-in detection of the optical intensity transmitted through a high gas concentration, as the emission wavelength of the laser is tuned by varying its temperature. The light intensity transmitted through the gas cell was normalised to a reference intensity, measured by splitting off part of the laser beam incident on the gas cell, thereby providing an absorption spectrum with a relatively flat baseline. This amplitude-modulated direct detection also allowed determination of the absorption linewidths. Targeting an absorption line the low detection limit was determined by removing the chopper and using the WMS technique at a modulation frequency of $90 \mathrm{kHz}$. The optimum modulation amplitude was determined from the linewidth of the direct-detected absorption lines. The sample Bragg grating sections were used to tune to wavelengths corresponding to known gas absorption lines at $1534.10\left(\mathrm{C}_{2} \mathrm{H}_{2}\right), 1541.18\left(\mathrm{CO}_{2}\right)$ and $1568.44 \mathrm{~nm}\left(\mathrm{H}_{2} \mathrm{~S}\right)$, previously determined by direct detection. Fine tuning of

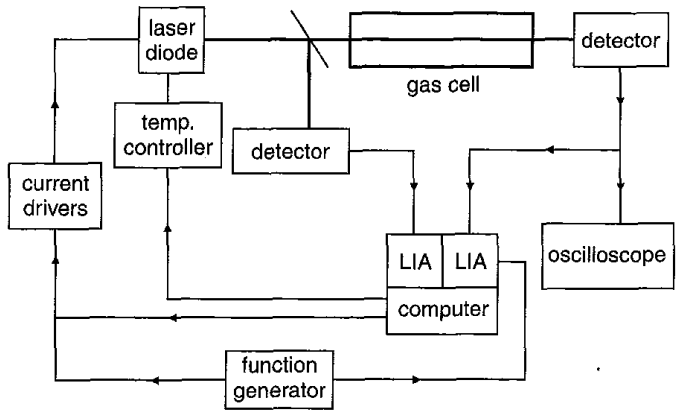

Fig. 5 Schematic diagram of WMS experimental setup for second harmonic detection 
the laser emission was controlled via the injection current $I_{g}$ into the gain section of the laser.

\section{Results and discussion}

A broad absorption spectrum of each gas over a few $\mathrm{nm}$ was taken by temperature tuning of the laser. The spectra for $\mathrm{CO}_{2}$ and $\mathrm{C}_{2} \mathrm{H}_{2}$ were measured using direct detection and in the case of $\mathrm{H}_{2} \mathrm{~S}$ a WMS technique was used. Direct detection of $\mathrm{H}_{2} \mathrm{~S}$ was not used since this would have necessitated using a relatively large quantity of this toxic gas that was considered unsafe in the laboratory. All measurements were taken with the gases at a room temperature of $22^{\circ} \mathrm{C}$.

The experimental setup used to detect $\mathrm{CO}_{2}$ included a stainless steel multipass sample cell with antireflection coated quartz windows. It had a path length of $50 \mathrm{~m}$ and was filled to one atmosphere with pure $\mathrm{CO}_{2}$. This long path length and large concentration was used since the targeted absorption lines of $\mathrm{CO}_{2}$ in the $1541 \mathrm{~nm}$ region are weak. Initially, the SG-DBR laser was temperature tuned over $10^{\circ} \mathrm{C}$ about room temperature with $I_{g}=80, I_{f}=7.54$, $I_{b}=12.1 \mathrm{~mA}$ and $I_{p}=$ open circuit, to detect the gas absorption lines as shown in Fig. $6 a$. The identity of the target gas line was confirmed by correlating its spectral position with $\mathrm{CO}_{2}$ absorption lines from the HITRAN database [10]. Subsequently the operating temperature of the laser was fixed at $21^{\circ} \mathrm{C}$ and the gain-section current was ramped over $30 \mathrm{~mA}$, scanning the wavelength over the $\mathrm{CO}_{2}$ gas absorption feature at $1541.18 \mathrm{~nm}$, while a small signal
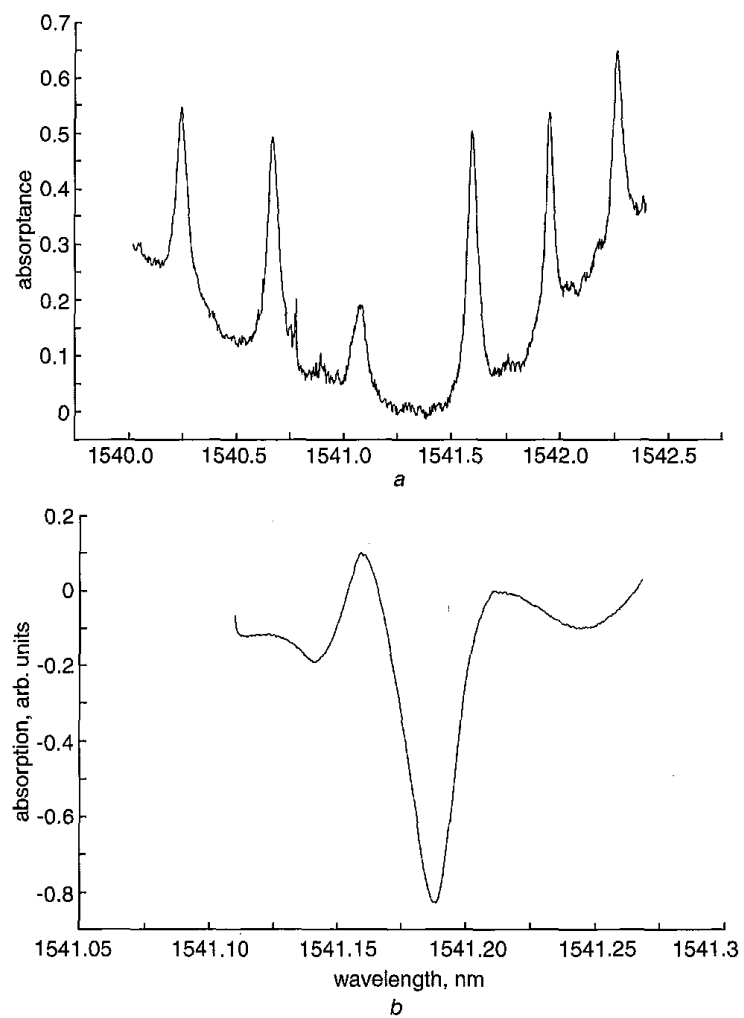

Fig. 6 Absorption spectrum and line for $\mathrm{CO}_{2}$

a $2 v_{1}+2 v_{2}+v_{3}$ overtone/combination band observed by temperature tuning at constant currents of $I_{g}=80, I_{f}=7.54, I_{b}=12.1 \mathrm{~mA}$, and $I_{p}=$ open circuit. Targeted species detected over path length of $50 \mathrm{~m}$

$b 2 f$ absorption line at $1541.18 \mathrm{~nm}$ using modulation frequency of $90 \mathrm{kHz}$ and by tuning gain section of laser over $30 \mathrm{~mA}$.
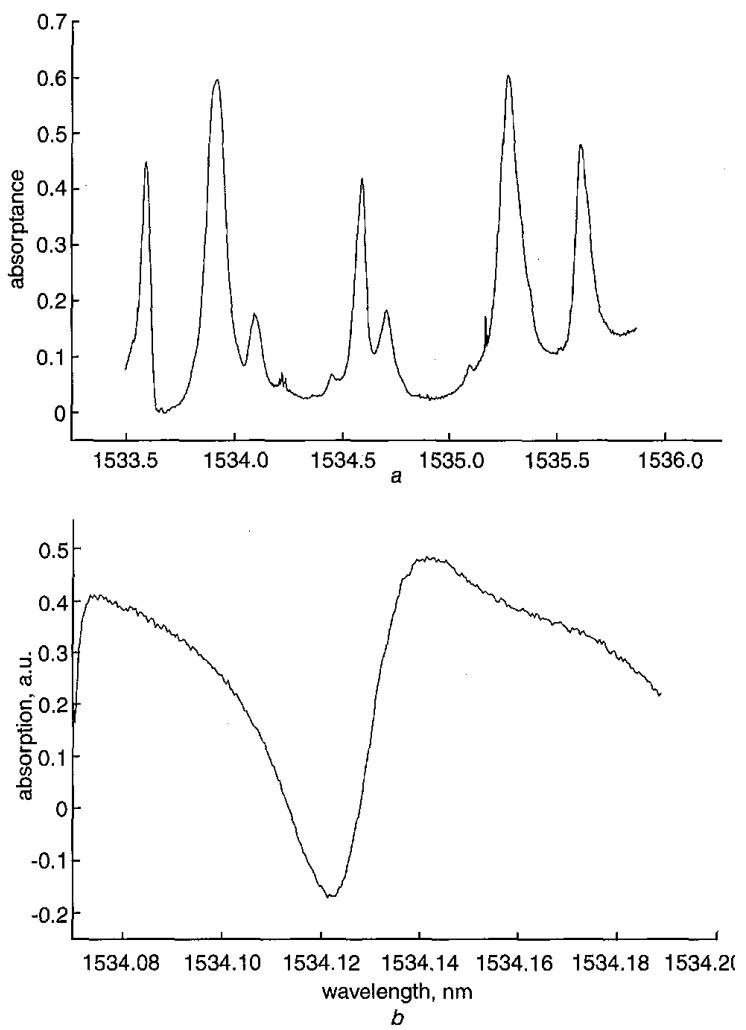

Fig. 7 Absorption spectrum and line for $\mathrm{C}_{2} \mathrm{H}_{2}$

$a v_{1}+v_{3}$ combination band of $\mathrm{C}_{2} \mathrm{H}_{2}$ observed by temperature tuning laser at constant currents of $I_{g},=80, I_{f}=8, I_{b}=10 \mathrm{~mA}$ and $I_{p}=$ open circuit. Targeted species was detected over path length of $33 \mathrm{~cm}$

$b 2 f$ absorption line of $\mathrm{C}_{2} \mathrm{H}_{2}$ at $1534.10 \mathrm{~nm}$ using modulation frequency of $90 \mathrm{kHz}$ and by tuning gain section of laser over $30 \mathrm{~mA}$.

current modulation was simultaneously applied to the laser. The resultant $2 f$ WMS spectrum is shown in Fig. $6 b$.

The directly detected $\mathrm{C}_{2} \mathrm{H}_{2}$ absorption lines in the $1530 \mathrm{~nm}$ region of the spectrum [14] are shown in Fig. $7 a$. An aluminium gas cell with antireflection coated quartz windows and an optical path length of $33 \mathrm{~cm}$, filled with 100 mbar of $\mathrm{C}_{2} \mathrm{H}_{2}$ and buffered with $\mathrm{N}_{2}$ to a pressure of one atmosphere was used. The emission wavelength of the diode was temperature tuned over $10^{\circ} \mathrm{C}$ with the gainsection current $I_{g}=80$ (a) $I_{f}=8, I_{b}=10 \mathrm{~mA}, I_{p}=$ open. The operating temperature of the laser was then set, as before, to a value of $21^{\circ} \mathrm{C}$ and the gain-section current was ramped over $30 \mathrm{~mA}$. The $\mathrm{C}_{2} \mathrm{H}_{2}$ gas absorption feature at $1534.1 \mathrm{~nm}$ was targeted and the resultant WMS spectrum is shown in Fig. $7 b$

$\mathrm{H}_{2} \mathrm{~S}$ absorption lines in the $1568.5 \mathrm{~nm}$ region of the spectrum were measured using a WMS technique and are shown in Fig. 8a. An sample gas cell of aluminium construction with antireflection coated quartz windows and an optical path length of $25 \mathrm{~cm}$, filled with $100 \mathrm{mbar}$ of $\mathrm{H}_{2} \mathrm{~S}$ and buffered with $\mathrm{N}_{2}$ to a pressure of one atmosphere was used. The emission wavelength of the diode was temperature tuned over $5^{\circ} \mathrm{C}$ with the gain section at a fixed current $I_{g}=80, I_{f}=2, I_{b}=0.6 \mathrm{~mA}$ and $I_{p}=$ open circuit. The absorption line at $1568.44 \mathrm{~nm}$ was targeted and with the laser temperature fixed as in the previous two cases at $21^{\circ} \mathrm{C}$, a WMS spectrum shown in Fig. $8 b$ was measured by current tuning the gain section of the laser.

With the removal and insertion of the appropriate gas cell into the optical set-up, all three gases were detected with a single SG-DBR laser tuning over a $30 \mathrm{~nm}$ range 

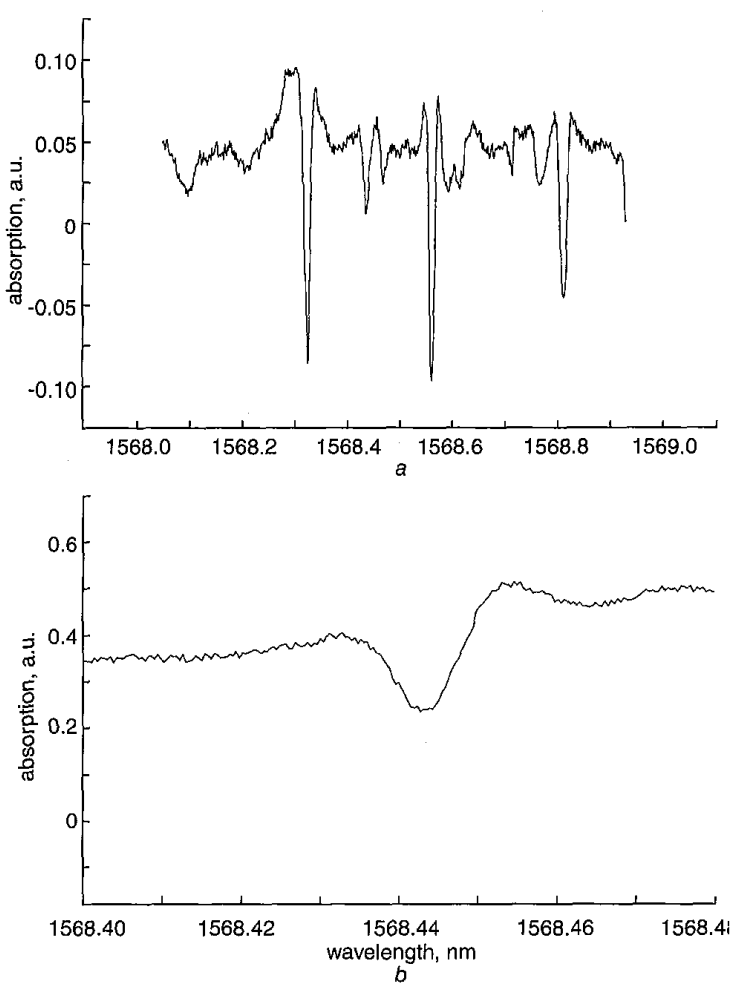

Fig. 8 2f absorption spectrum and line for $\mathrm{H}_{2} \mathrm{~S}$

a $v_{1}+v_{2}+v_{3}$ combination band of $\mathrm{H}_{2} \mathrm{~S}$ observed by temperature tuning a constant currents of $I_{g}=80, I_{f}=2, I_{b}=0.6 \mathrm{~mA}$ and $I_{p}=$ open circuit. Targeted species was detected over path length of $25 \mathrm{~cm}$

$b 2 f$ absorption line of $\mathrm{H}_{2} \mathrm{~S}$ at $1568.44 \mathrm{~nm}$ using modulation frequency of $90 \mathrm{kHz}$ and by tuning gain section of laser over $30 \mathrm{~mA}$.

operating at a fixed temperature of $21^{\circ} \mathrm{C}$. The measured $2 f$ absorption lines of the three gases were not the strongest shown in the wide spectra but are those that could be easily accessed with the laser at a fixed temperature of $21^{\circ} \mathrm{C}$ and the phase section open-circuit.

$\mathrm{C}_{2} \mathrm{H}_{2}$ exhibited an absorption feature that was broader than expected after pressure broadening effects have been taken into account, Fig. $7 b$. The possibility exists that the wavelength modulation of the laser overlaps with one or more adjacent absorption features, which are not resolved, due to a reduced spectral resolution at large wavelength modulation depths [15].

The line strength of the $\mathrm{H}_{2} \mathrm{~S}$ absorption at $1568.44 \mathrm{~nm}$ is weak, and is normally not the preferred wavelength for $\mathrm{H}_{2} \mathrm{~S}$. monitoring. Nevertheless, a good SNR was achieved. Absorption lines in the wavelength range $1.569 \leq \lambda \leq 1.613 \mu \mathrm{m}$ are preferred for $\mathrm{H}_{2} \mathrm{~S}$ sensing, where linestrengths are an order of magnitude greater than the absorption line used in the present experiments [9]. However, currently, widely tunable lasers with emission wavelengths greater than $1.6 \mu \mathrm{m}$ are not readily available to probe the stronger absorption lines of $\mathrm{H}_{2} \mathrm{~S}$.

The $2 f$ signature of $\mathrm{CO}_{2}$, similar to the situation with $\mathrm{C}_{2} \mathrm{H}_{2}$ and $\mathrm{H}_{2} \mathrm{~S}$, features a varying background, which in a real system would ultimately determine the sensitivity of any multigas detection instrument based on such a widely tunable laser. Further improvements in the detection sensitivity of the system are possible by increasing the modulation frequency to further overcome $1 / f$ type noise sources [11].

The SNR of the $2 f$ absorption signals for $\mathrm{C}_{2} \mathrm{H}_{2}$ and $\mathrm{H}_{2} \mathrm{~S}$, at wavelengths $\lambda=1534.10$ and $\lambda=1568.44 \mathrm{~nm}$, respec- tively, shown in Figs. $7 b$ and $8 b$ was measured. An integration time constant of $333 \mathrm{~ms}$ was set on the lockin amplifier. The SNR for $\mathrm{H}_{2} \mathrm{~S}$ and $\mathrm{C}_{2} \mathrm{H}_{2}$ detection were estimated to be 114 and 457 , respectively, where the peak to peak amplitude of the noise was used in the estimate. Assuming a linear relationship between the magnitude of the second harmonic WMS signal and gas concentration, the conventional method of estimating the low detection limit is by extrapolation from the magnitude of the measured WMS absorption signal to that signal level where the SNR is one. The minimum detectable limits [15] determined in this way for $\mathrm{H}_{2} \mathrm{~S}$ and $\mathrm{C}_{2} \mathrm{H}_{2}$ were found to be 103 and $39 \mathrm{ppm} . \mathrm{m} / \sqrt{ } \mathrm{Hz}$, respectively. The former value corresponds to a measured absorption detectivity of $6.0 \times 10^{-5}$ for the experimental set-up used.

The mode of operation used to tune across absorption features required operation of the sampled Bragg mirror sections at higher bias points to avoid supermode hops. As alluded to previously, this results in a reduction in the output power and ultimately to a deterioration of the SNR of the measurements. The variation in output power can also be attributed to the curvature of the comb reflection spectra envelope of the passive sampled grating section and the curvature of the active-section gain spectrum at the extremes of wavelength tuning [16].

The use of the sampled Bragg mirror sections to realise the tuning potential of the device requires the resolution of the current sources to be of the order of $\mu \mathrm{A}$. The foregoing measurements have been limited to current sources with $100 \mu \mathrm{A}$ resolution thus reducing the precision with which the wavelength can be programmed using $I_{f}$ and $I_{b}$.

Only the front and back grating sections have been used in the programming of the laser wavelength, where the avoidance of supermode jumps is foremost. Once a cavity lasing mode was selected it was continuously tuned by increasing the gain current. This results in the cavity mode being detuned from the grating mirror mode, resulting in a longitudinal mode hop. Such longitudinal mode hops can be controlled by biasing the phase section to tune the cavity mode into the mirror mode. This allows full access to all wavelengths within the laser tuning range.

\section{Conclusions}

Multigas detection has been achieved using a widely tunable SG-DBR laser diode as a light source using absorption spectroscopy. The characteristics (power, SMSR and wavelength tuning) of the SG-DBR laser were first measured. The integrated power collected was $500 \mu \mathrm{W}$ with both gratings unbiased and the laser temperature set to $25^{\circ} \mathrm{C}$. A typical maximum SMSR of $\geq 40 \mathrm{~dB}$ was measured. A tuning range of $30 \mathrm{~nm}$ at a constant laser temperature was achieved with the existing experimental set up. The SG-DBR laser was used in the detection and measurement of $\mathrm{C}_{2} \mathrm{H}_{2}, \mathrm{H}_{2} \mathrm{~S}$ and $\mathrm{CO}_{2}$ over a $30 \mathrm{~nm}$ laser tuning range, achieved by current tuning the device at a constant temperature. Minimum detection limits of 103 and 39 ppm.m $/ \sqrt{ } \mathrm{Hz}$, respectively, for $\mathrm{H}_{2} \mathrm{~S}$ and $\mathrm{C}_{2} \mathrm{H}_{2}$ were determined using the WMS technique.

The initial results with respect to the application of a SG-DBR laser to high-sensitivity, high-selectivity multigas sensing are encouraging. Obvious improvements include increased output power and the introduction of highresolution current sources when tuning the grating sections. Also, appropriate biasing of the phase section would control longitudinal-mode hops and allow greater access to wavelengths, facilitating enhanced quasicontin- 
uous coverage over the $30-\mathrm{nm}$ tuning range. This would enable access to additional gas absorption lines over the tuning range of the SG-DBR.

$\mathrm{H}_{2} \mathrm{~S}$ is known to exist in small concentrations as an impurity in $\mathrm{C}_{2} \mathrm{H}_{2}$ thus limiting safe exposure time to $\mathrm{C}_{2} \mathrm{H}_{2}$. Hence a method of simultaneous determination of $\mathrm{H}_{2} \mathrm{~S}$ and $\mathrm{C}_{2} \mathrm{H}_{2}$ concentrations has applications in the gas industry. The work described here demonstrates the application of widely tunable monolithic SG-DBR laser diodes, which were developed for the telecommunications industry, as a tunable spectroscopic source in multigas detection.

\section{Acknowledgments}

The authors thank Marconi Caswell technology for providing us with the diode used in the present work. We thank M. Lynch, and A. Lavin for their valuable contributions to this project.

\section{References}

1 JAYARMAN, V., MATHUR, A, COLDREN, L.A., and DAPKUS, P.D. 'Extended tuning range in sampled grating DBR Lasers', IEEE Photonics Technol. Lett., 1993, 5, (5), pp. 489-491

2 JAYARAMAN, V., CHUANG, Z.M., and COLDREN, L.A.: 'Theory, design, and performance of extended tuning range semiconductor lasers with sampled gratings', IEEE J. Quantum Electron, 1993, 29, (6), pp. with sampled

3 ISHII, H., TANOBE, H., KANO, F., TOHMORI, Y., KONDO, Y., and YOSHIKUNI, Y:: 'Quasicontinuous wavelength tuning in super-structure-grating SSG DBR lasers', IEEE J. Quantum Electron, 1996, 32, (3) pp. $433-440$

4 RIGOLE, P.J., NILSSON, S., BÄCKBOM, L., KLINGA, T., WALLIN, J, STÁLNACKE, B, BERGLIND, E., and STOLTZ, B.: '114 nm wavelength tuning range of a vertical grating assisted co-directional coupler laser with a super structure grating distributed Bragg reflector', IEEE Photonics Technol. Lett., 1995, 7, (7), pp. 697-699

5 UPSCHULTE, B.L., SONNENFROH, D.M., and ALLEN, M.G.: 'Measurements of $\mathrm{CO}, \mathrm{CO}_{2}, \mathrm{OH}$ and $\mathrm{H}_{2} \mathrm{O}$ in room temperature and combustion gases by use of a broadly current-tuned multi-section InGaAsP diode laser', Appl. Opt., 1999, 38, (9), pp. 1506-1512

6 IARSON, A.P. SANDSTRÖM, L., HÖJER, S, AHLBERG, H., and BROBERG, B.: 'Evaluation of distributed Bragg reflector lasers for high-sensitivity near infrared gas analysis', Opt. Eng., 1997, 36, (1), pp. $117-123$

7 MEASURES, R.M.: 'Laser remote chemical analysis' (Wiley, 1988) chapt. 3

8 PAVONE, F.S., MARIN, F., INGUSCIO, M., ERNST, K., and DILONARDO, G.: 'Sensitive Detection of Acetylene Absorption in the visible by using a stabilised AlGaAs diode laser', Appl. Opt., 1993, 32, (3), pp. $259-262$

9 ALLEN, H.C., and PLYLER, E.K.: 'Infrared spectrum of hydrogen sulphide in the $6290 \mathrm{~cm}^{-1}$ region', J. Res. Natl. Bur. Stand., 1954, 52, (4), pp. 205

10 ROTHMAN, L.S., GAMACHE, R.R., RISLAND, C.P., SMITH, M.A.H., CHRIS BENNER, D., MALATHY DEVI, V., FLAUD, J.M., CAMY-PEYRET, C., PERRIN, A., GOLDMAN, A., MASSIE, S.T., BROWN, L.R., and TOTH, R.A.: 'The HITRAN molecular database: editions of 1991 and 1992', J. Quant. Spectrosc. Radiat. Transfer, 1992, 48, pp. 469-502

11 REID, J., and LABRIE, D.: 'Second-harmonic detection with tunable diode lasers - Comparison of experiment and theory', Appl. Phys. B, 1981, 203-210, pp. 203-210

12 WELDON, V: 'Spectroscopic based gas sensing using single frequency near visible/infrared laser diodes'. 1997, $\mathrm{PhD}$ thesis, Trinity College, Dublin

13 SILVER, J.A.: 'Frequency-modulation spectroscopy for trace species detection: theory and comparison among experimental methods', Appl. Opt., 1992, 31, (6), pp. 707-717

14 BALDACCI, A., and GHERSETTI, S.: 'Interpretation of acetylene spectrum at $1.5 \mathrm{\mu m}$ ', J. Mol. Spectrosc., 1977, 68, pp. 183-194

15 WELDON, V, O'GORMAN, J PÉREZ-CAMACHO, JJ, MCDONALD, D., HEGARTY, J., and CORBETT, B.: 'Methane sensing with a novel micromachined single-frequency Fabry-Perot laser diode emitting at $1331 \mathrm{~nm}$, IEEE Photonics. Technol. Lett., 1997, 9, (3), pp. 357359

16 COLDREN, L.A., and CORZINE, S.W.: 'Continuously-tunable singlefrequency semiconductor lasers', IEEE J. Quantum Electron, 1987, QE23, (6), pp. 903-908 